\title{
New Proposal of Evaluation of the Thoracic Outlet
}

\author{
Bordoni Bruno ${ }^{1,2,3 *}$, Marelli Fabiola ${ }^{2,3}$, Morabito Bruno ${ }^{2,3,4}$, Sacconi Beatrice ${ }^{5}$ \\ ${ }^{1}$ Foundation Don Carlo Gnocchi IRCCS, Department of Cardiology, Institute of Hospitalization and Care with Scientific Address, \\ Milan, Italy \\ ${ }^{2}$ CRESO, School of Osteopathic Centre for Research and Studies, Aprile, Italy \\ ${ }^{3}$ CRESO, School of Osteopathic Centre for Research and Studies, Fano (Pesaro Urbino), Italy \\ ${ }^{4}$ Foundation Polyclinic University A. Gemelli University Cattolica del Sacro Cuore, Rome, Italy \\ ${ }^{5}$ Sapienza University of Rome, Radiological, Oncological and Anatomopathological Sciences, Rome, Italy \\ Email: *bordonibruno@hotmail.com
}

How to cite this paper: Bruno, B., Fabiola, M., Bruno, M. and Beatrice, S. (2018) New Proposal of Evaluation of the Thoracic Outlet. Open Journal of Therapy and Rehabilitation, 6, 17-42.

https://doi.org/10.4236/ojtr.2018.62003

Received: February 2, 2018

Accepted: April 15, 2018

Published: April 18, 2018

Copyright (c) 2018 by authors and Scientific Research Publishing Inc. This work is licensed under the Creative Commons Attribution International License (CC BY 4.0).

http://creativecommons.org/licenses/by/4.0/

\section{(c) (i) Open Access}

\begin{abstract}
The present article comprehensively reviews the thoracic outlet syndrome (TOS), its etiology and assessment, with reference to the usual conservative treatment and surgical therapy, highlighting new definitions and reporting obsolete tests. The syndrome affects about $8 \%$ of the population, with higher prevalence in females, and rarely affects the children. Conservative, non-surgical treatment produces good results, and it becomes important to know which specific areas need to be treated. Currently, there is no rehabilitation scheme, either osteopathic or chiropractic, considered as a valid tool for a precise localization of the pathologic condition, probably due to the lack of a manual assessment process to evaluate bones and muscular components of the thoracic outlet. In this situation, the manual treatment performed is usually generic. The present article proposes a manual evaluation that can be used to identify the anatomical area which needs to be treated. This hypothesis of assessment should be carried out after the clinician has ruled out the necessity of surgery with instrumental examinations.
\end{abstract}

\section{Keywords}

Thoracic Outlet Syndrome, Physiotherapy, Osteopathic, Chiropractic, Pain, Manual Evaluation, Fascia

\section{Introduction}

The first symptoms attributed to thoracic outlet syndrome (TOS) date back to 1818, even though the definition of TOS was definitively coined in 1956 [1]. The 
thoracic outlet is delimited: anteriorly, from the sternum manubrium, the sternoclavicular joint (SCC), the clavicle and by the acromioclavicular joint (AC); posteriorly, from the first costovertebral joint and the scapulothoracic joint (ST). Anatomists define this area as thoracic inlet, since it represents a passage for air and food; doctors define it as thoracic outlet, focusing the attention on vessels pathways [1]. The debate is purely academic. The neurovascular brachial plexus can be affected by pathologic processes which take in place in this region. The lowest roots of the brachial plexus pass through the triangular gap between the anterior and the middle scalene muscles (whose base is formed by the first rib), along with the subclavian artery (rarely penetrating the anterior scalene); this space is defined as the interscalene triangle [2]. The subclavian vein lies on the anterior scalene [3]. Then, the nerves and the subclavian vessels pass through an area delimited from the clavicle and the subclavian muscle superiorly and from the first rib inferiorly, named as costoclavicular space [2] [3]. Another potential site of neurovascular compression is the sub-coracoid tunnel, below the tendon of the pectoralis minor muscle [2] [3].

Symptoms resulting from TOS are various and complex, exacerbated by movements of the shoulder and neck; the syndrome affects about $8 \%$ of the population, with higher prevalence in females, and rarely in children [2]. According to recent definitions we can differentiate nervous and vascular compression, even according to the involved anatomic space: neurological TOS (nTOs) and vascular TOS (VTOS), when the first spaces are affected; neurological minor pectoralis muscle-PMM (nPMM) and vascular PMM (vPMM), when pathology is found at the level of sub-coracoid tunnel [3]. The nTOs sub-definitions have been abandoned: true (tnTOS), disputed (dnTOS), traumatic.

The tnTOS dealt with a neurological problem usually assessed with imaging studies and in presence of muscle atrophy; the dnTOS represents a similar condition, not assessed through clinical examination; according to another classification (traumatic), the cause could be represented by previous fractures to bone components of the thoracic outlet [3]. The first sub-classification is not true, as a neurological disorder is usually associated to vascular pathology [4]. The second one could cause confusion in diagnosis [3]. The last one was discarded, since the presence of previous fractures not necessarily lead to the syndrome [3]. The prevalence of nTOS ranges between $90 \%$ and $95 \%$, compared to VTOS; only $1 \%$ of the cases result from arterial compressions; however, neurological problems resulting from nPMM are not included in the mentioned data [3] [5] [6]. Compression or irritation of the brachial plexus always present with a triad of symptoms: pain; paresthesia; weakness [3] (see Table 1).

Symptoms of nTOS and nPMM overlap, involving pain or tenderness in the cervical spine and the trapezius muscle; all the upper limb or part of it may be interested. Paresthesia or numbness can affect one or more fingers; the weakness appears only after several months as the difficulty to grab [3]. To differentiate between the two components, in the presence of nTOS the pain to the cervical 
Table 1. nTOS/nPMM Symptoms.

\begin{tabular}{l}
\hline Pain or soreness \\
\hline - Cervicaltract \\
- Trapezius \\
- Supraclavicular area \\
- Axilla \\
- Upper arm (shoulder, elbow, forearm, hand) \\
- Chest \\
\hline Paresthesia \\
\hline - Fingers \\
\hline Weakness \\
\hline - Upper arm (shoulder, elbow, forearm, hand) \\
\hline
\end{tabular}

and occipital area is more frequent, while in patients with nPMM pain involves the anterior aspect of the chest and the armpit; both conditions are present in frequent cases [3]. The pain can occur during the day, with daily activities, or at night, or in both situations [2]. Other symptoms are cold sensation and Raynaud phenomenon, probably due to irritation of the sympathetic nervous system causing vasoconstriction [5]. Less common symptoms are the vertigo and dizziness, tinnitus, tachycardia and pseudoangina [2].

Venous obstructions present similar symptoms in VTOS and vPMM (see Table 2).

The axillo-subclavian vein obstruction can occur with or without thrombotic changes; in case of thrombus, symptoms such as swelling of the extremities, feelings of pressure and cyanosis are constant and intense, without relation with the movements, persisting for days or weeks [3]. The presence of thrombus is also classified as thrombosis stress syndrome or Paget-Schroetter, while the absence of thrombotic changes is defined as McCleery syndrome [1]. In the absence of a venous thrombus, symptoms may decrease when the arm is at rest [3]. Pain and paresthesias are not always present; if paresthesia is present, it is usually caused by pressure in the region of the hand level and not from in the thoracic outlet [3] [5]. The arterial obstructions, less common but more dangerous (they can lead to gangrene), in the presence of VTOS/vPMM can cause similar symptoms (see Table 3).

Pathologic conditions may involve the subclavian and axillary arteries, due to compression, stenosis and aneurysms; blood flow to the arm is reduced, producing symptoms which do not clarify the origin of the occlusion (subclavian or axillary artery) [3]. The typical symptoms are fatigue in moving the arm, unilateral Raynaud phenomenon, pallor, cyanosis and hyper-sensitivity to cold; there is a discoloration and ischemia of fingers [3]. Arm claudication is also present. The subclavian artery can completely occlude, with potential onset of gangrene [1]. Symptoms related to vPMM are similar but less intense; pain and paraesthesia can appear, because the axillary nerve can be compressed in the quadrangle 
Table 2. vTOS/vPMM venous symptoms.

\begin{tabular}{l}
\hline Upper extremity \\
- Swelling \\
- Cyanosis \\
- Tightness \\
- Fullness \\
\hline Non thrombotic obstruction \\
\hline - Intermittent symptoms \\
\hline Thrombotic obstruction \\
\hline - Constant symptoms \\
\hline
\end{tabular}

Table 3. vTOS/vPMM arterial symptoms.

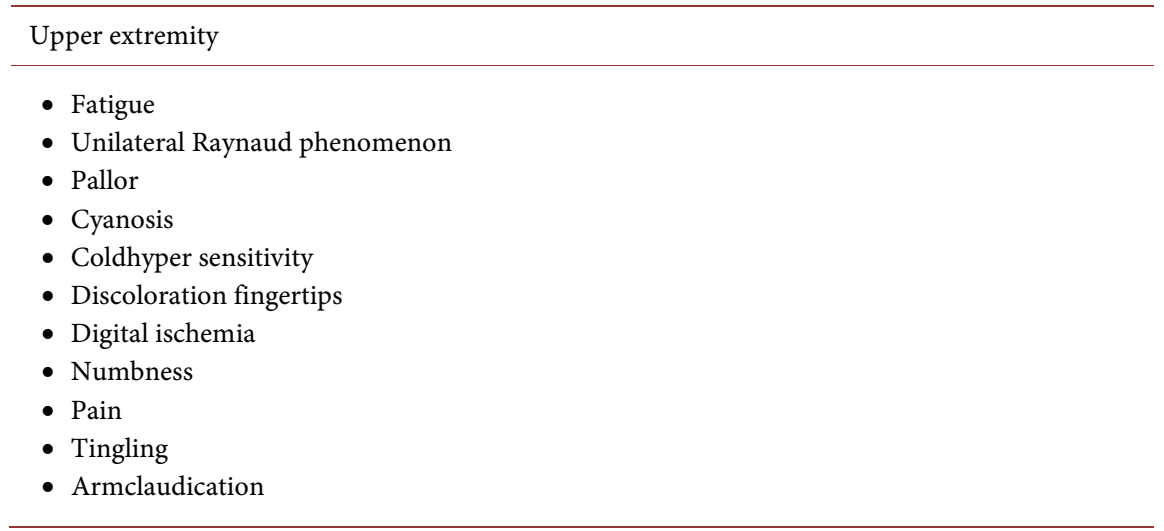

of Velpeau, together with the humeral posterior circumflex artery, branch of the axillary artery [3]. Rarely the involvement of the subclavian artery can cause symptoms in neck and shoulders, since emboli or thrombi may have retrograde pathways [5].

\section{Etiology}

Surgeons diagnose nTOS about 100 times more frequently than neurologists [7]. Frequent causes are bone or tissue abnormalities or traumatic changes.

A cervical rib is present in about $1 \%$ of the population, where $70 \%$ are women; the presence of this bone anomaly is often asymptomatic, while in case of cervical trauma it can become a cause of compression of the brachial plexus, in particular in hypertension [3] [5]. An elongated transverse process of C7 is another congenital variation potentially leading to nTOS. It is virtually always associated with the presence of a ligament or fascial tissue, which connects the transverse process with the body of the first or second rib, crossing the middle scalene muscle [3]. It is asymptomatic in most cases but it can be symptomatic after cervical trauma [3]. Other causes are related to anatomical abnormalities could of other components of the thoracic outlet, such as muscle groups with abnormal insertions or dimensions (scalene, pectoralis minor, subclavian), ligaments too lose or too fibrotic, bony insertions with abnormal position or size, supernume- 
rary muscles [5] [7]-[12]. Even the brachial plexus could present abnormalities causing nTOS, such as direct crossing of muscles [13].

Work or sports habits inducing the complete abduction of the shoulder may, in the presence or absence of anatomical abnormalities, cause the syndrome, continuously reducing the anatomic space for the brachial nerve passage; or, the in case of raising a weight repeatedly (condition in which the scapula is pushed against the rib cage), an excessive tension is caused on the pectoralis minor [3]. All the articular structures of the thoracic outlet are potentially at risk of causing nTOS, which appears when one or more causes limit their range of motion, such as trauma or other pathologies [7].

Other causes of nTOS are related to the pleural dome, since anatomic or functional abnormalities of the pulmonary apex at the level of the first rib could lead to brachial nerves compressions [14]. In the presence of chronic obstructive pulmonary disease (COPD), the diaphragm assumes a position of inspiration, increasing lung pressures; we can hypothesize that such pressures and the position of the diaphragm can lead to nTOS, for example for elevation of the first rib and hypertrophy of the scalene muscles [15] [16] [17].

Vascular compression of the subclavian vein can happen in the space between the clavicle (top), the first rib (bottom), the subclavian muscle/ligament costoclavicular (lateral-upper) and the scalene muscle (lateral); less common is a compression of the axillary vein under the pectoralis minor [3]. Repeated venous compression, trauma or repetitive motion, hypertrophy of the anterior scalene and subclavian muscle, skeletal abnormalities lead to inflammation of the vessel intima, breaking the delicate balance between formation and destruction of clots; thickening and fibrosis of the vessel lumen can lead to scars and vascular stenosis [3] [18]. Significant alteration of blood flow in the presence of inflammation may lead to trombotic change [3]. A stenosis may also occur in presence of foreign bodies, such as catheters or wires in the vein (pacemaker) [3] [18]. The presence of coagulopathy (genetic abnormality of factor 5 , deficiency of protein $\mathrm{C}$ or S, and other types) can cause defects in coagulation, in particular if presence of predisposing factors (abnormalities of the structures of the thoracic outlet), acute or repetitive trauma, or movements described to be associated with the onset of nTOS [3].

Pathologic conditions related to the axillary and subclavian arteries represent about $1 \%$ of the TOS, although they can lead to dangerous situations, such as gangrene of the fingers or arm [3]. Compressions can cause stenosis, occlusions and aneurysms; for the subclavian artery common causes are found in bone abnormalities (cervical rib, post-traumatic callus of the clavicle as result of previous fractures, and anatomical anomalies between the coast and the clavicle); other causes are represented by muscle abnormalities, also found for nTOS [19] [20]. Subclavian artery compression is common in sports where athletic movement requires the complete abduction of the arm, with potential arterial embolism; embolism is usually distal to the site of compression, but retrograde 
thrombosis can happen [19]. The reasons are the same that lead to the formation of clots in veins [19] [20]. Aneurysms and post-stenotic ectasia can be observed [20]. Compression of the axillary artery is often caused by abnormal traction of the posterior circumflex humeral artery, often for repeated movements or trauma of the humeral head [3] [19] [21]. These abnormal tensions in the artery can damage the intima, with potential aneurysmatic or trombotic changes [3] [19] [21] (see Table 4).

\section{TOS Assessment: State of the Art}

The assessment begins with the medical history interview and a clinical examination, in order to compare the arm with the contralateral one [2] [7]. Active limb movements are globally observed (shoulder, elbow and wrist), with special attention to the onset of any symptoms [7] [19]. Patient's posture has to be observed, since an altered body alignment may cause stress to the thoracic outlet, such as an abnormal position of the shoulders or scapula (projecting or falling shoulder, or winged scapula) [2] [19]. Then, the palpation of the limb and painful area needs to be performed, even without a precise procedure, as well as the passive mobilization of the different components [2]. The strength of the various muscles of the limb and thoracic outlet has to be tested; then a neurological examination must be performed [2]. Classical orthopedic and neurological tests must be performed in order to rule out any other underlying cause of the symptoms, such a disc hernia, rupture of the rotator cuff, multiple sclerosis, chronic pain syndrome, peripheral nerve entrapment [6]. Anyway, a reliable evaluation process for the assessment of the syndrome is currently missing; few tests can be used, but they show low diagnostic accuracy [1] [18].

Table 4. Etiology.

\begin{tabular}{l} 
nTOS \\
\hline - Cervicalrib \\
- Anomaliestransverseprocess of C7 \\
- Enlarged scalene tubercole \\
- Scalene musclehypertrophy \\
- Supernumerarymuscle \\
- Work or sportshabits \\
- Pulmonarydisease \\
\hline VTOS venous \\
\hline - Paget-Schroettersyndrome \\
- McCleerysyndrome \\
- Coagulopathies \\
- Foreignbodies \\
\hline VTOS arterial \\
\hline - Osseousabnormality \\
- Muscularabnormality
\end{tabular}


Before instrumental tests are performed, other tests have to be performed, the so-called provocative tests. The rotation of the head actively performed by the patient, in the presence of TOS, may trigger the symptoms on the opposite side, such as pain and paresthesia; the same event may occur if the patient tilts his head toward the shoulder (head tilting) [3] [5]. Such tests are performed to activate the contralateral brachial plexus. The upper limb tension test of Elvey (ULTT) is performed; in the first phase the patients abducts the limb to 90 degrees in neutral position (palm down) and elbow straight, with head straight; then, in the second phase of the test, the patient dorsiflects the wrists. In the last phase of the test the patient tilts the head towards the shoulder [5]. In each phase the brachial plexus stretching is increased; the first and second positions stimulate the appearance of ipsilateral symptoms, while the third position cause symptoms on the opposite side [5].

An immediate onset of symptoms is suspicious for a highly compromised situation, while a late appearance of the symptoms is considered less serious [5].

Another test is the elevated arm stress test of Roos (EAST). In this test, the patient has to abduct the shoulder at 90 degrees with the elbows bent at right angles, with the hand palms face forward; then the patient is asked to close and open his hands alternatively for 3 minutes [2] [3]. The examiner observes the changes that may occur, such as a falling arm, an alteration of skin color and asks if other symptoms appear [2] [3]. During this test the space for the passage of the brachial neurovascular bundle is reduced [2] [3].

Another test is the $90^{\circ}$ AER (ninety degree abduction in external rotation stress); in this test the patient is asked to abduct the arm in external rotation to 90 degrees (the palms are faced up) [3] [5]. The active movement reduced the space for the brachial plexus [3] [5]. These tests can be performed consecutively [3].

A test considered obsolete, with too many false positives, is the Adson's test. The patient rotates and tilts his head to one side, remaining in inspiratory apnea for 30 seconds or in normal breathing for a minute, while the examiner evaluates the radial pulse of the ipsilateral side; if the radial pulse disappears, there is a vascular compression in the thoracic outlet [2]. The test is now considered unreliable [3] [7]. The measurement of the blood pressure is a fast way to assess the presence of any vascular problems. In patients with a compressed arterial lumen, a difference of more than $20 \mathrm{mmHg}$ in systolic blood pressure between the two arms is considered as a significative value [19]. The diagnosis of TOS can be complicated by the presence of the so-called "double crush syndrome", in which peripheral neurological symptoms (ulnar or carpal compression), probably depending on tensions at the level of the brachial plexus at the thoracic outlet, can interfere with the diagnosis [1] [2] [22]. If the tests for the TOS are all positive (false negatives are rare), instrumental tests are performed [3]. To differentiate nTOS and vTOS, the first examinations are a radiograph and/or a CT scan, in particular for bone abnormalities [1] [5]. An electrophysiological assessment of 
nerve conduction can be obtained through electromyography (EMG) and the evaluation of nerve conduction velocity (NCV); slow electrical conduction (less than $85 \mathrm{~m} / \mathrm{s}$ ) and a decreased action potential indicate nerve compression [1] [5]. These electrophysiological evaluations, in combination with ultrasound, may be employed after an anesthetic block on scalene muscles or the pectoralis minor, to verify if the nerve response improves, or if the symptomatic area remain silent at palpation; a good response is strongly suspicious for the presence of nTOS [3]. The neurography can show abnormalities of the brachial plexus position, but it is less used for its costs.3 MRI can give false positive results [3]. To verify a VTOS venous type, a duplex ultrasound scan can be used, with a high sensitivity $(78 \%-100 \%)$ and high specificity $(82 \%-100 \%)$; if the interpretation remains uncertain, venography can lead to the correct diagnosis [1] [3] [18]. For a problem of arterial origin, duplex ultrasound scan can be used; then, other tests such as MRI, CT and arteriography may be performed [3] [19] [20].

\section{Treatment: State of the Art}

The decision on the type of treatment (conservative or surgical treatment) has to be taken based on the symptoms and on instrumental and clinical information. Conservative treatment for nTOS and nPMM includes several approaches: physiotherapy (massage, stretching, muscle strengthening or relaxation, postural and breathing exercise), with or without associated drugs and physical therapies (ultrasound, laser, magnetotherapy); osteopathy (articular and muscular techniques); chiropractic (articular technique); acupuncture [1] [3] [23] [24] [25].

There is no specific conservative treatment protocol [25]. Despite the lack of a homogenous protocol, $60 \%-70 \%$ of patients with brachial nerve compression reported an improvement of the symptoms [6]. This improvement would be even more evident in comparison with surgery [26]. The main purpose of surgical treatment in the presence of nTOS and nPMM is to remove the cause of compression, for example through full or partial resection of the first rib, scalenectomy (anterior or medial muscle); tenotomy of the pectoralis minor; partial resection of the pectoralis minor [2] [3] [23]. Symptoms recurrence is observed in about $10 \%-20 \%$ of patients who underwent surgery for neurological compression [3]. In patients with VTOS and/or VPMM venous type, the conservative treatment is represented only by anticoagulation and compression therapy [27]. This approach is not completely accepted, with drug therapy alone we risk a recurrence of the clot formation; the indication of compression is deduced especially for lower limbs [18]. Surgical treatment for venous compressions of VTOS and/or vPMM consists in: thrombolysis with direct access via venous catheter (in case of thrombosis); mechanical aspiration of thrombus from the vein (if the occlusion does not allow thrombolysis); angioplasty (if the patient still shows venous symptoms); resection of the first rib; anterior scalenectomy; reconstructive surgery [2] [3] [6] [18] [23]. The venous surgical treatment shows good results $(85 \%-100 \%$ of resolution), especially if surgery is performed shortly after 
the onset of symptoms [3] [6] [18].

There is no conservative treatment for arterial occlusion [19]. In the presence of VTOS and/or VPMM with arterial compression surgery is the best option: resection of the first rib and hypertrophic muscles; embolectomy; artery surgical repair (with synthetic prostheses); venous or arterial bypass (saphenous vein, carotid artery) [2] [3] [20] [21] [23].

The results of surgical treatment on symptoms resolution are good (about $80 \%)$ [3]. The surgical approach to be used depends on the patient's needs.

\section{New Proposal of Manual Evaluation of the Thoracic Outlet}

There is not a conservative protocol universally considered as the best one; existing ones are not specific, or do not fully involve all the components of the thoracic outlet. Specific conservative therapeutic procedures are not available, and a proper evaluation of the results is not possible, since a complete manual evaluation of the musculoskeletal components is currently missing. We propose a hypothesis of manual evaluation.

This hypothesis of assessment should be carried out after than the clinician has ruled out the necessity of surgery with instrumental examinations. The same doctor may use this manual evaluation to get the first summary information on the area less mobile and sore. The physiotherapist, osteopath or chiropractor should know what the precise area that needs conservative intervention is; the operator will be able to know in detail where to work, only with a comprehensive assessment of thoracic outlet.

Palpation is an important tool to evaluate, classify and make diagnosis; the fingertip has a tactile sensitivity and is able to evaluate objects measured in micron [28] [29] [30] [31]. Palpation is able to report the position of the joints and to recognize abnormal joint movements, tissue abnormalities (temperature, tone, hardness) from the surface to the depth of the various layers, and to identify the painful area [30] [32] [33].

The evaluation protocol consists of three phases, lasting about 15 minutes, with the patient standing, sitting and being supine.

\subsection{First Phase: The Patient Standing}

With the patient standing and the operator behind him, D1 spinous process has to be grab with the index and the thumb, producing delicate side shift movements (see Figure 1).

The same action is repeated for the D2 spinous process, since the second rib articulates with a facet of D1, influencing D2 too. This induced movement shows whether there is some movement restriction, pain onset or an excessive range of motion. The dorsal vertebrae affect the movements of the shoulder joint; during ipsilateral abduction, the thoracic vertebrae bend and rotate, while during bilateral abduction, the vertebral bodies are extendend [34]. The pain can be caused not only by the adjacent muscle tissues, but also by the costovertebral 


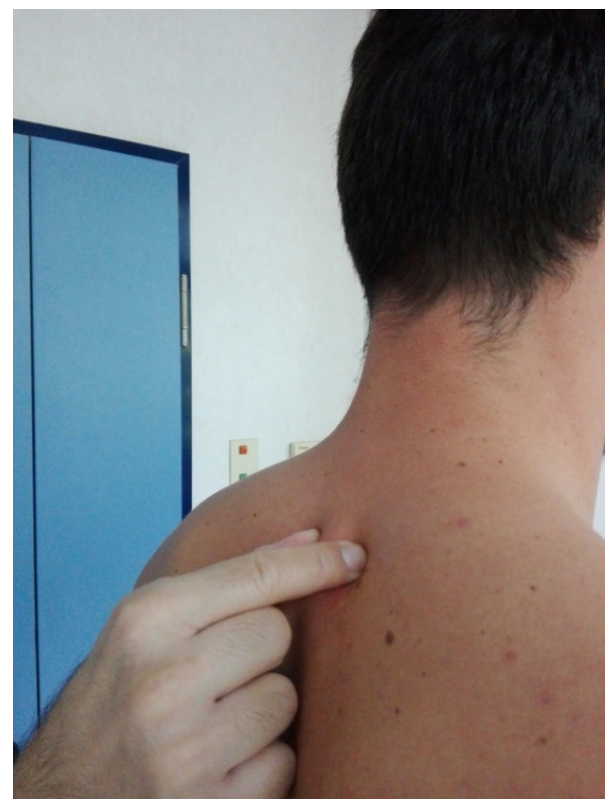

Figure 1. With the patient standing and the operator behind him, D1 spinous process has to be grab with the index and the thumb, producing delicate side shift movements.

and costotransverse joints [35]. Since they are innervated joints (by the sympathetic system and the lateral branches of the dorsal thoracic branches), the can be a source of pain in asymptomatic patients when stimulated, or produce pain in case of articular restrictions [35] [36].

Then the D1 spinous process is held, while the free hand index leans laterally to the transverse process of the same vertebra; the patient is asked to make deep inhalations and exhalations, in order to allow the cost-transverse joint palpation (see Figure 2).

During the inhalation, the joint is "closed", while during exhalation it is "open", maintaining the dorsal respiratory interaction in optimal dynamic conditions [37]. The examination is repeated for the contralateral side and also for D2. To successfully evaluate the cost-transverse joint, a line branching off perpendicularly from the mastoid process towards the rib tubercle has to be imaged; the joint is located medially to this line [38]. This joint can generate pain, thanks to the presence of neuropeptides which communicate with the somatic and autonomic system (Substance P, calcitonin-gene-related peptide, neuropeptide Y) [39]. A restriction of mobility of the thoracic vertebrae and the joints between the ribs and the vertebral bodies can affect the shoulder movements, the clavicle and the scapula, causing a compressive syndrome [34] [40] [41].

Then the scapular mobility must be evaluated. The motor control of the scapula depends on the trapezius muscle, allowing the movement of the arm in different planes [41]. The scapula moves on a sliding plane on the chest surface with rotations and translations (abduction-adduction, elevation-depression; internal-external rotation), being affected by spinal position, the humerus and the 


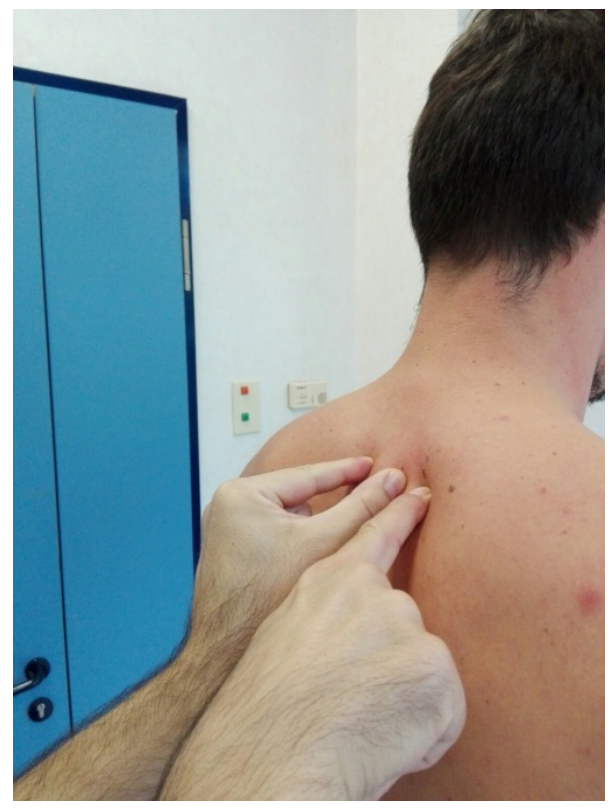

Figure 2. The D1 spinous process is held, while the free hand index leans laterally to the transverse process of the same vertebra; the patient is asked to make deep inhalations and exhalations, in order to allow the costotransverse joint palpation.

acromionclavicular joint [42]. The scapula, when unable to perform all movements, could cause a TOS syndrome [25]. The operator's hands hold the patient's shoulders and, with gentle movements, drag the scapula in the different directions (cranial, caudal, right and left, lateral and medial rotation) (see Figure 3).

A very little manual strength has to be used to move the scapula, without bothering the patient, in order to perceive any movement restrictions [43].

Then the shoulder has to be evaluated. The operator holds with his hands the middle third of the arm, and poses a slight downward traction, evaluating the tissue resistances (see Figure 4).

During this phase, movement restrictions or excessive laxity of the muscle-joint complex of the shoulder can be perceived [43] [44]. In patients diagnosed with TOS there is an abnormal shoulder position; in some subjects the shoulder can be high (with probable impingement syndrome) or low (drooping shoulder syndrome) [40] [45] [46] [47] [48] [49]. A correct assessment of shoulder position and quality of the muscular tissues allows to plan a rehabilitation process including reinforcement, or stretching activities. The shoulder has an important role in the dynamics leading to the diagnosis of TOS; abnormal voltage it negatively affects the vascular-nervous brachial plexus [3] [19] [21]. The shoulder joint is crucial in the management of mechanical stresses moving from the posterior area of the chest towards the sternum, and vice versa; if this mechanism is altered, pathologic conditions may happen [34] [50] [51]. 


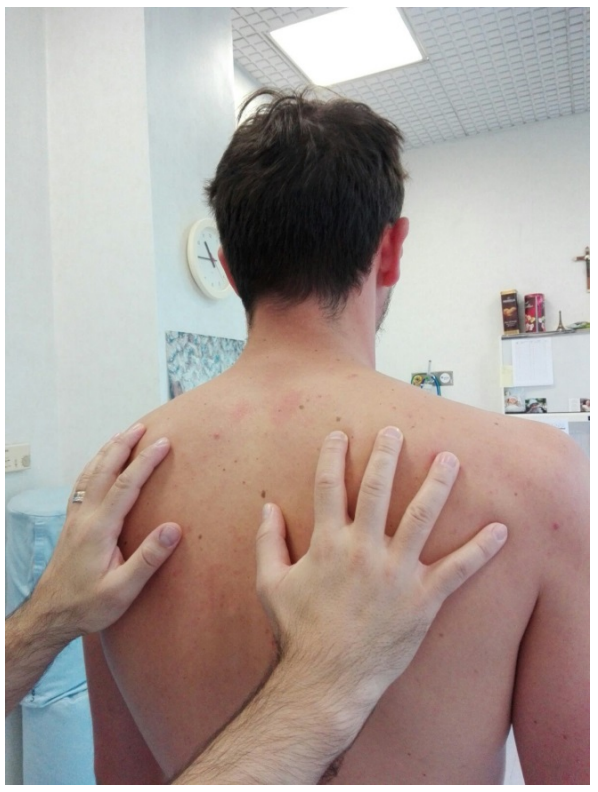

Figure 3. The operator's hands hold the patient's shoulders and, with gentle movements, drag the scapula in the different directions (cranial, caudal, right and left, lateral and medial rotation).

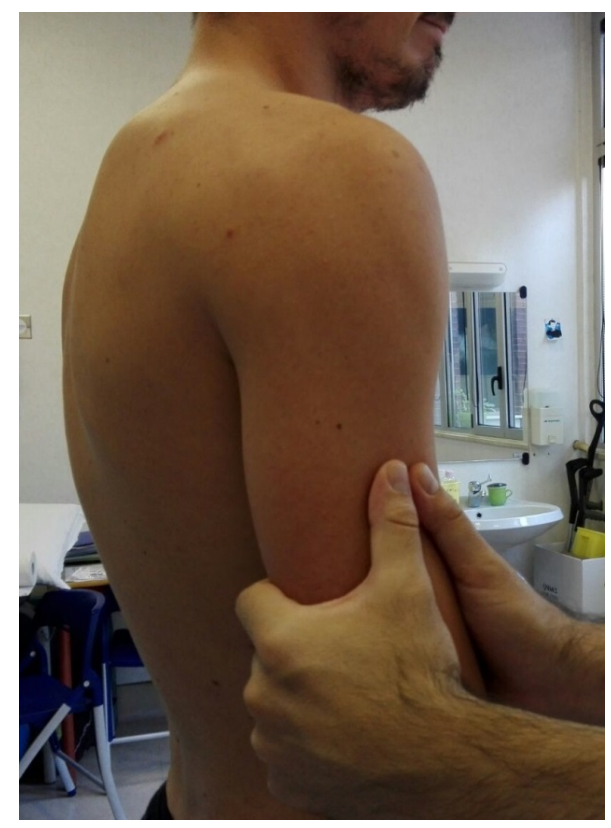

Figure 4. The operator holds with his hands the middle third of the arm, and poses a slight downward traction, evaluating the tissue resistances.

\subsection{The Second Phase: The Patient Being Seated}

The second phase of the thoracic assessment concerns the acromioclavicular joint (ACJ), with the patient being seated and the operator standing at his side. 
With one finger on the ACJ, the operator holds the patient's forearm with the other hand; then internal and external rotations of the shoulder joint must be performed to verify joint compliance and consistency (see Figure 5 and Figure 6).

The ACJ is involved in the stabilization of the entire shoulder complex, enabling mechanical stresses to translate from the clavicle to the scapula and viceversa [52].

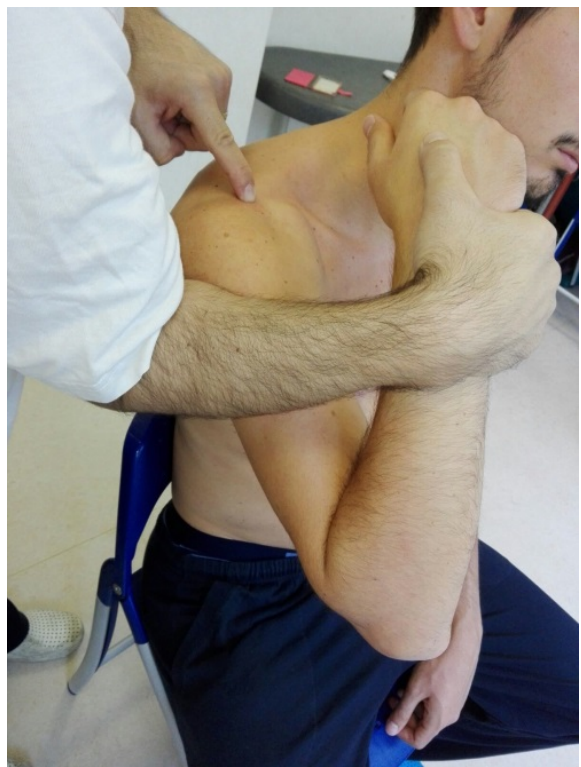

Figure 5. With one finger on the ACJ, the operator holds the patient's forearm with the other hand.

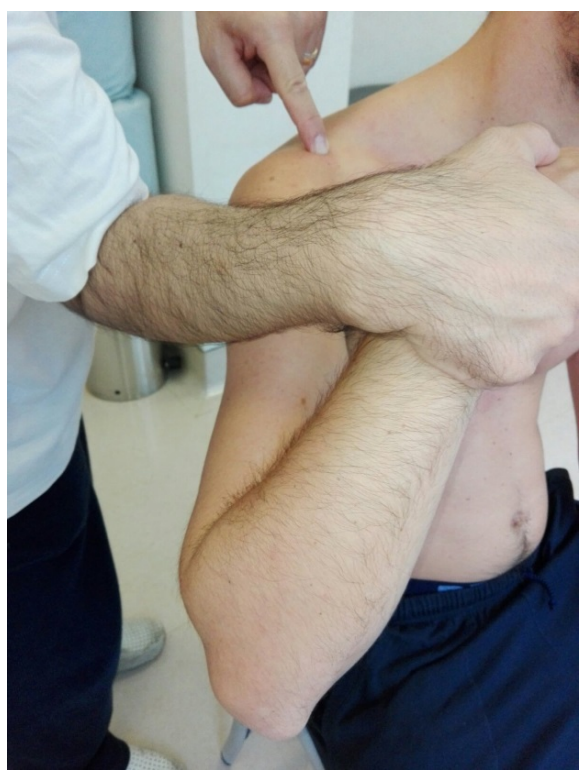

Figure 6. Internal and external rotations of the shoulder joint must be performed to verify joint compliance and consistency. 
Over time the meniscus joint tends to deteriorate, adversely affecting the joint performance; two ligaments (upper and lower acromionclavicular ligaments) stabilize it; the upper one is connected with some fibers of the trapezius muscle [52] [53]. The joint can be evaluated through palpation, in particular to evaluate the voltage in the upper acromioclavicular ligament; with an internal rotation and adduction of the shoulder the ACJ "is closed", reducing the ligament voltage, while with an external rotation in abduction the ligamentous tension is maximum, with the ACJ being "open" (a small depression is perceived at palpation) [52] [54]. The joint is innervated by the lateral pectoral nerves and the suprascapular nerve with sensory fibers, becoming a source of pain in the presence of functional alteration [54]. If this joint does not show regular performance, it may become cause of instability of the shoulder joint complex, and cause of symptoms related to the TOS [3] [19] [21] [52].

\subsection{The Third Phase: The Patient being Supine}

The third and final step of the manual inspection is carried out with the patient being supine. The operator's hands grab the supraclavicular trapezius area, pulling the muscles towards himself (see Figure 7).

In this way, the tone can be perceived and any abnormalities of the cervical-dorsal portion can be detected. The trapezius muscle is flat and wide, involving the cervical and thoracic spine, including the first two thoracic vertebrae, the $\mathrm{ACJ}$ and the posterior edge of the distal third of the clavicle [49]. The trapezius has a fundamental role in the movements of scapula and clavicle, which is brought back and raised during muscular contraction (especially with the abduction of the arm), due to the indirect action on the sternoclavicular joint [55]. An altered muscle tone may adversely affect the costoclavicular space; to know whether the muscle needs a reinforcement or inhibition could make the difference in the rehabilitation and conservative process.

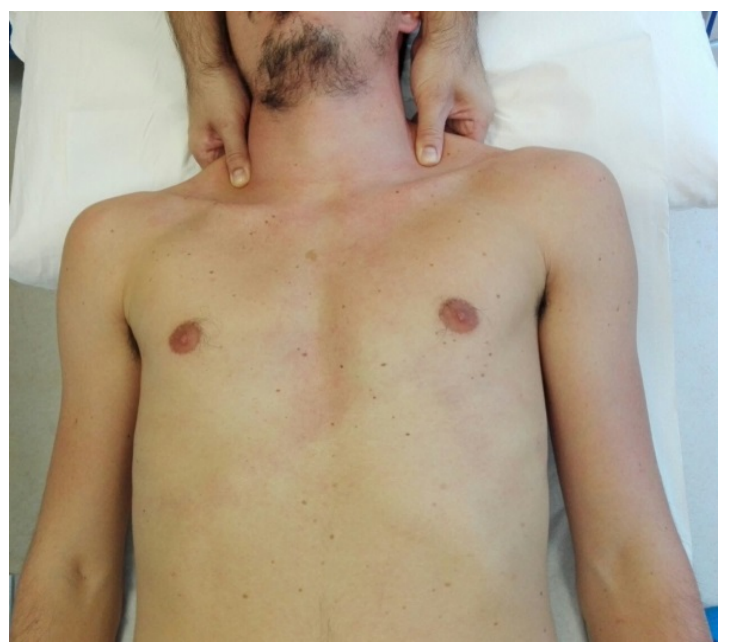

Figure 7. The operator's hands grab the supraclavicular trapezius area, pulling the muscles towards himself. 
The first rib must be examined bilaterally, evaluating the posterior area of the neck with the fingers until the neck base; the medial aspect of the firs rib is perceived as a hard formation which varies its position according to the breath [56] (see Figure 8).

Once the first rib is detected by using thumbs, the rib must be pushed caudally pushing, to verify its elasticity; otherwise, always by using thumbs, the operator can verify if one rib is more raised than the contralateral one in inspiration, by asking for deep inspirations (the first rib raised), and expirations (the first rib lowers) [38]. The movement is known as the bucket handle [37] [38]. A positional alteration is a frequent cause of TOS [38].

The operator is standing next to the patient supine, and the evaluation goes on. A portion of the brachial plexus can be palpated, especially in the supraclavicular area. The patient's head can tilt towards the other side (not palpated), while the operator looks for the subclavian artery at the level of the middle third of the clavicle; a portion of the plexus can be evaluated over the subclavian artery and laterally to the anterior scalene muscle [7] [56] [57] (see Figure 9).

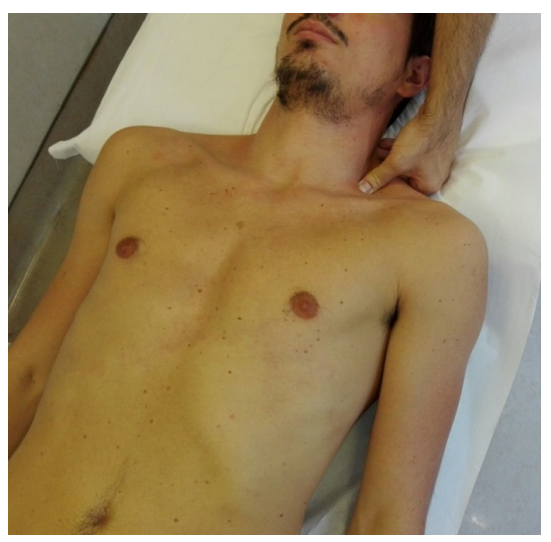

Figure 8. The first rib must be examined bilaterally, evaluating the posterior area of the neck with the fingers until the the neck base; the medial aspect of the firs rib is perceived as a hard formation which varies its position according to the breath.

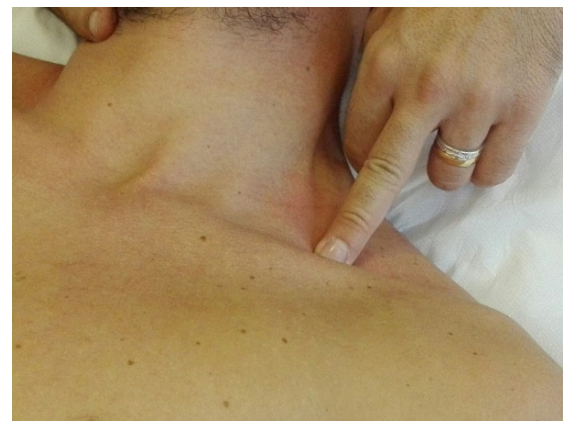

Figure 9. The patient's head can tilt towards the other side (not palpated), while the operator looks for the subclavian artery at the level of the middle third of the clavicle; a portion of the plexus can be evaluated over the subclavian artery and laterally to the anterior scalene muscle. 
Nerve palpation is feasible and can highlight a tenderness of the area, suggesting pathological condition of the fascial structure that covers the nerves, such as compression or abnormal traction [58]. Both sides must be evaluated and compared.

Then tone and/or presence of pain in the pectoralis minor muscle must be evaluated. The thumb must be cranially pushed under the axillar region towards the coracoid insertion of the muscle, with oblique orientation [59] (see Figure 10).

This step is useful to understand the health status of the muscle; an altered tone or presence of pain can be a symptom of TOS [6] [59]. The evaluation of the subclavian muscle is simple: the operator's fingers are placed below the clavicle, particularly in the middle third of the bone, perceived as a small strip of compact tissue (see Figure 11).

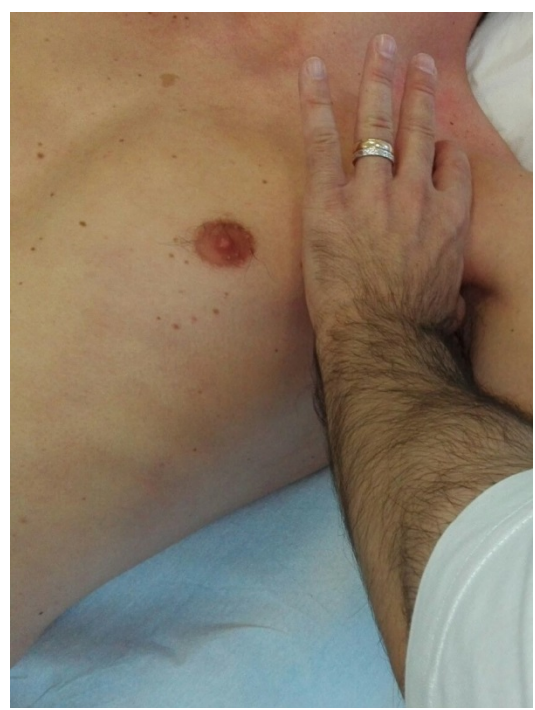

Figure 10. The thumb must be cranially pushed under the axillar region towards the coracoid insertion of the muscle, with oblique orientation.

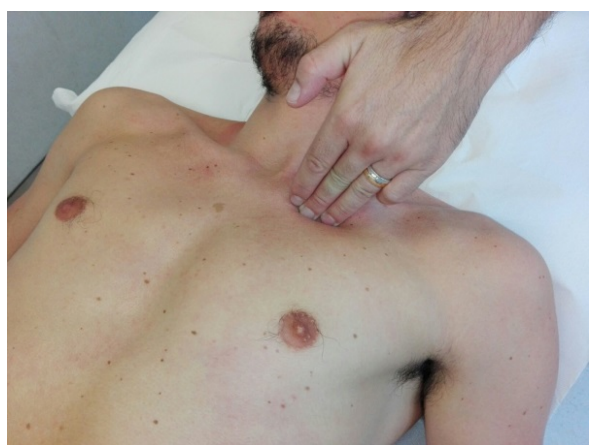

Figure 11. The evaluation of the subclavian muscle is simple: the operator's fingers are placed below the clavicle, particularly in the middle third of the bone, perceived as a small strip of compact tissue. 
It may be sore and hypertrophic, as potential sign of TOS [60]. The subclavian muscle affects the ACJ and sterno-clavicular joints, with depressions actions of the clavicle, resulting in shoulder's lowering [52].

The following assessment phase concerns the clavicular bone. The clavicle is grab with one hand, with the fingers leaning on the back edge of the bone (the thumb is free); the other hand holds the patient's arm and maintains the forearm pressed between his arm and the flank. Circling of the clavicle are performed, in order to mimic the three-dimensionality of its axes of motion, while the hand is held on the clavicle to facilitate movements (see Figure 12).

The shoulder passive movements (involving the clavicle) let us perceive if there are movement restrictions or pain [55]. The clavicle is able not only to transmit the mechanical stresses laterally (sternum, scapula and chest), but also medially (to the soft tissue structures such as muscles, viscera and vascular-nervous brachial plexus) [61].

Then the hypothenar eminence must be placed on the sternal manubrium, while the other hand is above the previous one; in this way, pain and movement restrictions of the adjacent structures can be evaluated (see Figure 13).

The manubrium may be subject to conditions that cause pain and restriction of movement; alteration of its position can cause functional deficiency of associated structures (the first two ribs and the clavicle) and cause TOS [62] [63]. The first two sterno-costal joints must be evaluated also. The hypothenar eminence must be placed on the manubrium with a slight perpendicular pressure, while the index and middle fingers are placed on the first two cartilages; the patient is asked to make a deep inhalation and exhalation, allowing to assess whether the ribs are able to move freely or if pain occurs (see Figure 14).

The scheme must be repeated for the opposite side. By blocking the manubrium the first ribs are forced to compensate for the restriction induced on the sternum, showing the potential presence of anterior hypomobility of ribs. If the ribs do not move properly anteriorly, the corresponding vertebrae lose their motion ability, resulting in pathologic conditions of the thoracic outlet [43].

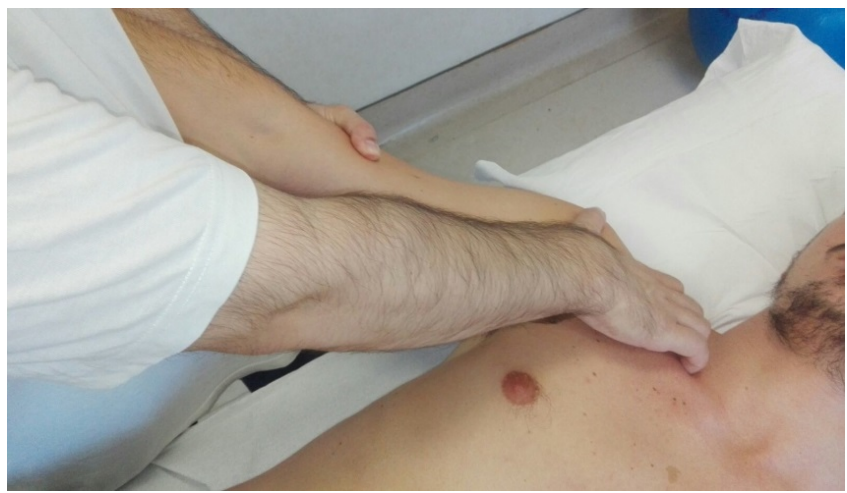

Figure 12. Circling of the clavicle are performed, in order to mimic the three-dimensionality of its axes of motion, while the hand is held on the clavicle to facilitate movements. 


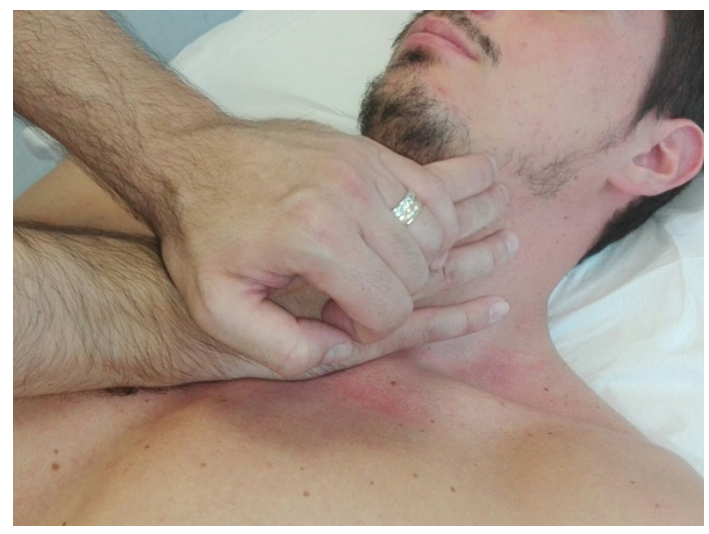

Figure 13. The hypothenar eminence must be placed on the sternal manubrium, while the other hand is above the previous one; in this way, pain and movement restrictions of the adjacent structures can be evaluated.

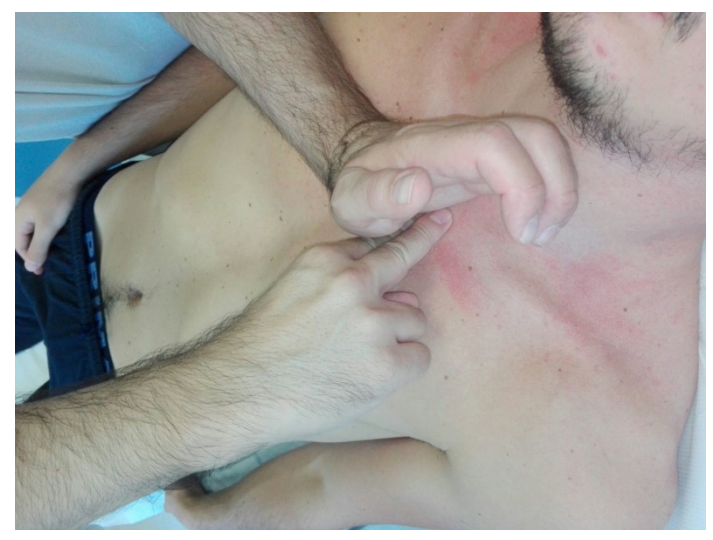

Figure 14. The hypothenar eminence must be placed on the manubrium with a slight perpendicular pressure, while the index and middle fingers are placed on the first two cartilages; the patient is asked to make a deep inhalation and exhalation, allowing to assess whether the ribs are able to move freely or if pain occurs.

For the sternumclavicular joint (SCJ), the thumb must be placed over the joint while the other hand grasps the patient's arm in the same way used for the evaluation of the clavicle; the patient's arm is flexed (to 90 degrees), inducing in the shoulder anteposition and retroposition (see Figure 15).

The presence of pain and restriction of movement must be tested. The SCJ allows to the medial portion of the clavicle the execution of anterior and posterior movements, with a joint complex controlling the fluctuation ranges (costoclavicular and sternoclavicular); a dysfunction of the SCJ can cause the development of TOS and related symptoms [7].

The movements of the shoulder are integrated by the contribution of ACJ and SCJ; SCJ is innervated by C3-C6 branches, with potential pain and irradiation 
[34] [64]. The evaluation of this area is important, because it may be asymptomatic in many patients with TOS if not actively solicited by an operator [65]. In the last part of the manual assessment the scalene muscles are palpated to perceive their tone, even testing their elastic ability; for this evaluation, the operator is placed posteriorly to the patient's head. For the right side, the first rib is held with the hypothenar eminence in the supraclavicular fossa, avoiding its rising during the stretch of the scalene muscles; for the anterior scalene, the patient's head tilts to the left and simultaneously turns to the right side (see Figure 16).

For the middle scalene, the head bends to the left without rotations, respecting the functional anatomy of these two muscles [66] (see Figure 17).

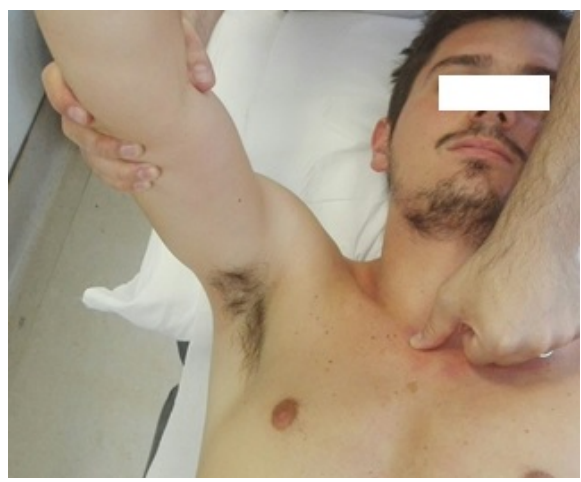

Figure 15. The thumb must be placed over the joint while the other hand grasps the patient's arm in the same way used for the evaluation of the clavicle; the patient's arm is flexed (to 90 degrees), inducing in the shoulder anteposition and retroposition.

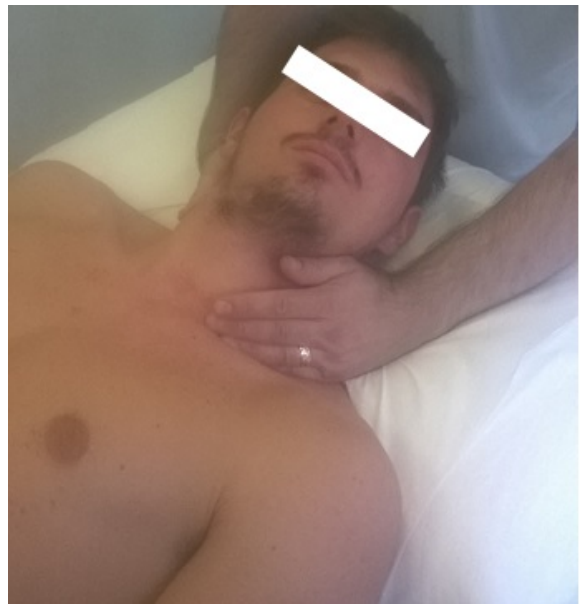

Figure 16. For the right side, the first rib is held with the hypothenar eminence in the supraclavicular fossa, avoiding its rising during the stretch of the scalene muscles; for the anterior scalene, the patient's head tilts to the left and simultaneously turns to the right side. 


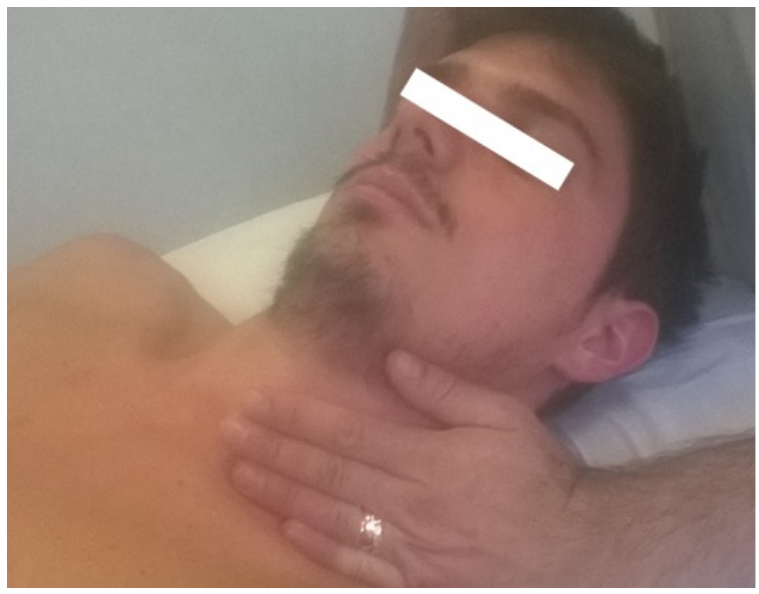

Figure 17. For the middle scalene, the head bends to the left without rotations, respecting the functional anatomy of these two muscles.

The hand (the one placed on the rib) is useful to understand when the stretching of the muscle involves the insertion area, with an additional passive movement of the head. Abnormal tension in the muscle (and often painful to induced movements), will result in a reduced excursion [43]. Tension and pain the anterior and middle scalene muscles can be frequent causes of TOS [6].

The two scalene muscles affect the cervical transverse processes (C2-C7), with insertions on the first rib [67]. The scalene musculature (including the posterior scalene) can fatigue during a repeated respiratory effort, in particular in patients suffering from chronic obstructive pulmonary disease, in which these contractile districts are often over-stimulated and hypertonic in comparison with healthy subjects [68] [69]. These muscles are very important for breathing and for the movements of the thoracic outlet. The final part of the evaluation is related to an osteopathic palpation dealing with the thoracic outlet and its ability to expand and retract. The anatomic space of the thoracic outlet must continually expand and retract, even though with a limited extent, to adapt the changes of movement of muscles, bones, internal organs, nervous, vascular and lymphatic structures [6] [43]. This palpation represents the last part of the manual examination, performed in order to have a final global vision, to obtain confirmation of the areas characterized by restriction of mobility. The hands must be placed on the thoracic outlet, with the index being placed above the clavicle and the other fingers underneath, while the thumbs are placed posteriorly, at the level of the first dorsal vertebra (see Figure 18).

By training, over time, the operator becomes able to evaluate changes induced during expansion and retraction of the anatomic space [43] [44] (see Table 5).

We hope that this article could represent a starting point and a stimulus for further research in the field of manual evaluations, and improve knowledge are still missing [70] [71]. 


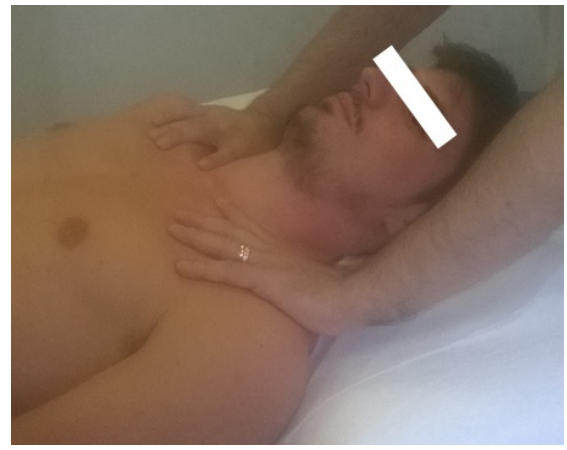

Figure 18. The hands must be placed on the thoracic outlet, with the index being placed above the clavicle and the other fingers underneath, while the thumbs are placed posteriorly, at the level of the first dorsal vertebra.

Table 5. Manual evaluation.

Patient standing

Lateral translation D1-D2; Transverse process; Scapular mobility; Shoulder mobility

Seatedpatient

Acromioclavicular joint

Supine patient

Trapezius muscle; First rib; Brachial plexus; Pectoralis minor muscle; Subclavius muscle; Clavicula; Sternal manubrium; Sterno-costaljoints; Sterno-clavicular joint; Scalene muscles; Osteopathic palpation thoracic outlet

\section{Conclusion}

The thoracic outlet syndrome (TOS) is caused by compression in certain anatomical areas of the vascular-nervous brachial plexus, between the scalene triangle, the clavicle, the first rib and the pectoralis minor. It is an insidious syndrome, not always easy to be managed, whose curative approach can be conservative and/or surgical. A comprehensive osteopathic manual evaluation of this musculoskeletal anatomical area is currently missing; in this scenario, a specific conservative therapeutic procedure cannot be properly assessed, and therapeutic results are not easily evaluated. The present article suggests a potential manual evaluation, which could highlight the anatomical area or areas that need more therapeutic attention. This kind of approach may potentially lead to higher results of non-surgical approach therapeutic techniques. The authors auspicate that this article could represent a starting point and a stimulus for further research in the field of manual evaluations.

\section{Disclosure}

The authors report no conflicts of interest in this work. 


\section{Authors' Contributions}

Bruno Bordoni, article writing, figures insertion; Fabiola Marelli, Bruno Morabito, text correction; Beatrice Sacconi, article translation.

\section{References}

[1] Klaassen, Z., Sorenson, E., Tubbs, R.S., Arya, R., Meloy, P., Shah, R., Shirk, S. and Loukas, M. (2014) Thoracic Outlet Syndrome: A Neurological and Vascular Disorder. Clinical Anatomy, 27, 724-732. https://doi.org/10.1002/ca.22271

[2] Watson, L.A., Pizzari, T. and Balster, S. (2009) Thoracic Outlet Syndrome Part 1: Clinical Manifestations, Differentiation and Treatment Pathways. Manual Therapy, 14, 586-595. https://doi.org/10.1016/j.math.2009.08.007

[3] Sanders, R.J. and Annest, S.J. (2014) Thoracic Outlet and Pectoralis Minor Syndromes. Seminars in Vascular Surgery, 27, 86-117. https://doi.org/10.1053/j.semvascsurg.2015.02.001

[4] Ahn, S.S., Miller, T.J., Chen, S.W. and Chen, J.F. (2014) Internal Jugular Vein Stenosis Is Common in Patients Presenting with Neurogenic Thoracic Outlet Syndrome. Annals of Vascular Surgery, 28, 946-950. https://doi.org/10.1016/j.avsg.2013.12.009

[5] Sanders, R.J., Hammond, S.L. and Rao, N.M. (2007) Diagnosis of Thoracic Outlet Syndrome. Journal of Vascular Surgery, 46, 601-604.

https://doi.org/10.1016/j.jvs.2007.04.050

[6] Freischlag, J. and Orion, K. (2014) Understanding Thoracic Outlet Syndrome. Scientifica, 2014, Article ID: 248163. https://doi.org/10.1155/2014/248163

[7] Hooper, T.L., Denton, J., McGalliard, M.K., Brismée, J.M. and Sizer, P.S. (2010) Thoracic Outlet Syndrome: A Controversial Clinical Condition. Part 1: Anatomy, and Clinical Examination/Diagnosis. Journal of Manual \& Manipulative Therapy, 18, 74-83. https://doi.org/10.1179/106698110X12640740712734

[8] Muellner, J., Kaelin-Lang, A., Pfeiffer, O. and El-Koussy, M.M. (2015) Neurogenic Thoracic Outlet Syndrome due to Subclavius Posticus Muscle with Dynamic Brachial Plexus Compression: A Case Report. BMC Research Notes, 8, 351. https://doi.org/10.1186/s13104-015-1317-3

[9] Natsis, K., Totlis, T., Didagelos, M., Tsakotos, G., Vlassis, K. and Skandalakis, P. (2013) Scalenus Minimus Muscle: Overestimated or Not? An Anatomical Study. The American Surgeon, 79, 372-374.

[10] Paraskevas, G., Ioannidis, O., Papaziogas, B., Natsis, K., Spanidou, S. and Kitsoulis, P. (2007) An Accessory Middle Scalene Muscle Causing Thoracic Outlet Syndrome. Folia Morphologic, 66, 194-197.

[11] Yildizgören, M.T., Ekiz, T., Kara, M., Yörübulut, M. and Ozçakar, L. (2014) Magnetic Resonance Imaging of a Fibrous Band Causing True Neurogenic Thoracic Outlet Syndrome. American Journal of Physical Medicine \& Rehabilitation, 93, 732-733. https://doi.org/10.1097/PHM.0000000000000090

[12] Liu, J.E., Tahmoush, A.J., Roos, D.B. and Schwartzman, R.J. (1995) Shoulder-Arm Pain from Cervical Bands and Scalene Muscle Anomalies. Journal of the Neurological Sciences, 128, 175-180. https://doi.org/10.1016/0022-510X(94)00220-I

[13] Leonhard, V., Smith, R., Caldwell, G. and Smith, H.F. (2016) Anatomical Variations in the Brachial Plexus Roots: Implications for Diagnosis of Neurogenic Thoracic Outlet Syndrome. Annals of Anatomy-Anatomischer Anzeiger, 206, 21-26. https://doi.org/10.1016/j.aanat.2016.03.011 
[14] Collins, J.D. (2016) Unsuspected Herniated Lung Obstructing the Right Internal Jugular Vein and Internal Carotid Artery in a Patient with Thoracic Outlet Syndrome: MRI/MRA and MRV. Journal of the National Medical Association, 108, 106-112. https://doi.org/10.1016/j.jnma.2016.03.001

[15] Bordoni, B., Marelli, F., Morabito, B. and Sacconi, B. (2016) Manual Evaluation of the Diaphragm Muscle. International Journal of Chronic Obstructive Pulmonary Disease, 11, 1949-1956. https://doi.org/10.2147/COPD.S111634

[16] Agrawal, D., Vohra, R., Gupta, P.P. and Sood, S. (2007) Subclinical Peripheral Neuropathy in Stable Middle-Aged Patients with Chronic Obstructive Pulmonary Disease. Singapore Medical Journal, 48, 887-894.

[17] Bortolani, E., Miani, S., D’Armini, A., Gallo, E. and Morbidelli, A. (1989) Role of Anterior Scalene Musclehypertrophy in Thoracic Outlet Syndrome. Minerva Chirurgica, 44, 1305-1309.

[18] Moore, R. and Lum, Y.W. (2015) Venous Thoracic Outlet Syndrome. Vascular Medicine, 20, 182-189. https://doi.org/10.1177/1358863X14568704

[19] Daniels, B., Michaud, L., Sease, F., Cassas, K.J. and Gray, B.H. (2014) Arterial Thoracic Outlet Syndrome. Current Sports Medicine Reports, 13, 75-80. https://doi.org/10.1249/JSR.0000000000000034

[20] Criado, E., Berguer, R. and Greenfield, L. (2010) The Spectrum of Arterial Compression at the Thoracic Outlet. Journal of Vascular Surgery, 52, 406-411. https://doi.org/10.1016/j.jvs.2010.03.009

[21] Durham, J.R., Yao, J.S., Pearce, W.H., Nuber, G.M. and McCarthy III, W.J. (1995) Arterial Injuries in the Thoracic Outlet Syndrome. Journal of Vascular Surgery, 21, 57-70. https://doi.org/10.1016/S0741-5214(95)70244-X

[22] Leffert, R.D. (1992) Thoracic Outlet Syndromes. Hand Clinics, 8, 285-297.

[23] Hooper, T.L., Denton, J., McGalliard, M.K., Brismée, J.M. and Sizer Jr., P.S. (2010) Thoracic Outlet Syndrome: A Controversial Clinical Condition. Part 2: Non-Surgical and Surgical Management. Journal of Manual \& Manipulative Therapy, 18, 132-138. https://doi.org/10.1179/106698110X12640740712338

[24] Streit, R.S. (2014) NTOS Symptoms and Mobility: A Case Study on Neurogenic Thoracic Outlet Syndrome Involving Massage Therapy. Journal of Bodywork and Movement Therapies, 18, 42-48. https://doi.org/10.1016/j.jbmt.2013.04.007

[25] Watson, L.A., Pizzari, T. and Balster, S. (2010) Thoracic Outlet Syndrome Part 2: Conservative Management of Thoracic Outlet. Manual Therapy, 15, 305-314. https://doi.org/10.1016/j.math.2010.03.002

[26] Landry, G.J., Moneta, G.L., Taylor Jr., L.M., Edwards, J.M. and Porter JM. (2001) Long-Term Functional Outcome of Neurogenic Thoracic Outlet Syndrome in Surgically and Conservatively Treated Patients. Journal of Vascular Surgery, 33, 312-317. https://doi.org/10.1067/mva.2001.112950

[27] Brooke, B.S. (2016) Conservative Management of Chronic Upper Extremity Venous Outflow Occlusion. Phlebology: The Journal of Venous Disease, 31, 34-40. https://doi.org/10.1177/0268355516631860

[28] Martingano, D., Gurm, H., Oliff, A., Martingano, F.X. and Aglialoro, G. (2016) Osteopathic Approach to the Diagnosis of Appendiceal Mucinous Cystadenocarcinoma Mimicking Primary Ovarian Malignant Neoplasm. The Journal of the American Osteopathic Association, 116, 480-484. https://doi.org/10.7556/jaoa.2016.092

[29] Bordoni, B. and Zanier, E. (2015) Sutherland's Legacy in the New Millennium: The Osteopathic Cranial Model and Modern Osteopathy. Advances in Mind-Body Medicine, 29, 15-21. 
[30] Chaitow, L. (2012) The ARTT of Palpation? Journal of Bodywork and Movement Therapies, 16, 129-131. https://doi.org/10.1016/j.jbmt.2012.01.018

[31] Kasparian, H., Signoret, G. and Kasparian, J. (2015) Quantification of Motion Palpation. The Journal of the American Osteopathic Association, 115, 604-610. https://doi.org/10.7556/jaoa.2015.121

[32] Shaw, K.A., Dougherty, J.J., Treffer, K.D. and Glaros, A.G. (2012) Establishing the Content Validity of Palpatory Examination for the Assessment of the Lumbar Spine Using Ultrasonography: A Pilot Study. The Journal of the American Osteopathic Association, 112, 775-782. https://doi.org/10.7556/jaoa.2012.112.12.775

[33] Elkiss, M.L. and Jerome, J.A. (2012) Touch-More than a Basic Science. The Journal of the American Osteopathic Association, 112, 514-517.

[34] Crosbie, J., Kilbreath, S.L., Hollmann, L. and York, S. (2008) Scapulohumeral Rhythm and Associated Spinal Motion. Clinical Biomechanics, 23, 184-192. https://doi.org/10.1016/j.clinbiomech.2007.09.012

[35] Young, B.A., Gill, H.E., Wainner, R.S. and Flynn, T.W. (2008) Thoracic Costotransverse Joint Pain Patterns: A Study in Normal Volunteers. BMC Musculoskeletal Disorders, 9, 140. https://doi.org/10.1186/1471-2474-9-140

[36] Fruth, S.J. (2006) Differential Diagnosis and Treatment in a Patient with Posterior Upper Thoracic Pain. Physical Therapy, 86, 254-268.

[37] Beyer, B., Sholukha, V., Dugailly, P.M., Rooze, M., Moiseev, F., Feipel, V. and Van Sint Jan, S. (2014) In Vivo Thorax 3D Modelling from Costovertebral Joint Complex Kinematics. Clinical Biomechanics, 29, 434-438. https://doi.org/10.1016/j.clinbiomech.2014.01.007

[38] Loyd, B.J., Gilbert, K.K., Sizer, P.S., Atkins, L.T., Sobczak, S., Brismée, J.M. and Pendergrass, T.J. (2014) The Relationship between Various Anatomical Landmarks Used for Localizing the First Rib during Surface Palpation. Journal of Manual \& Manipulative Therapy, 22, 129-133. https://doi.org/10.1179/2042618613Y.0000000064

[39] Dedrick, G.S., Sizer, P.S., Sawyer, B.G., Brismeè, J.M. and Smith, M.P. (2011) Immunohistochemical Study of Human Costotransverse Joints: A Preliminary Investigation. Clinical Anatomy, 24, 741-747. https://doi.org/10.1002/ca.21137

[40] Theisen, C., van Wagensveld, A., Timmesfeld, N., Efe, T., Heyse, T.J., Fuchs-Winkelmann, S. and Schofer, M.D. (2010) Co-Occurrence of Outlet Impingement Syndrome of the Shoulder and Restricted Range of Motion in the thoracic Spine-A Prospective Study with Ultrasound-Based Motion Analysis. BMC Musculoskeletal Disorders, 11, 135. https://doi.org/10.1186/1471-2474-11-135

[41] De Baets, L., Van Deun, S., Monari, D. and Jaspers, E. (2016) Three-Dimensional Kinematics of the Scapula and Trunk, and Associated Scapular Muscle Timing in Individuals with Stroke. Human Movement Science, 48, 82-90. https://doi.org/10.1016/j.humov.2016.04.009

[42] Seth, A., Matias, R., Veloso, A.P. and Delp, S.L. (2016) A Biomechanical Model of the Scapulothoracic Joint to Accurately Capture Scapular Kinematics during Shoulder Movements. PLoS ONE, 11, e0141028. https://doi.org/10.1371/journal.pone.0141028

[43] Chila, A.G. (2010) Foundations for Osteopathic Medicine. 3rd Edition, Lippincott Williams and Wilkins, Philadelphia, PA.

[44] DiGiovanna, E., Schiowtz, S. and Dowling, D. (2004) An Osteopathic Approach to Diagnosis and Treatment. 3rd Edition, Lippincott Williams and Wilkins, Philadelphia, PA. 
[45] Park, J.Y., Oh, K.S., Yoo, H.Y. and Lee, J.G. (2013) Case Report: Thoracic Outlet Syndrome in an Elite Archer in Full-Draw Position. Clinical Orthopaedics and Related Research, 471, 3056-3060. https://doi.org/10.1007/s11999-013-2865-2

[46] Lee, J.H., Choi, H.S., Yang, S.N., Cho, W.M., Lee, S.H., Chung, H.H., Shin, J.S. and Kim, D.H. (2011) True Neurogenic Thoracic Outlet Syndrome Following Hyperabduction during Sleep-A Case Report. Annals of Rehabilitation Medicine, 35, 565-569. https://doi.org/10.5535/arm.2011.35.4.565

[47] Cho, Y.J., Lee, H.J., Gong, H.S., Rhee, S.H., Park, S.J. and Baek, G.H. (2012) The Radiologic Relationship of the Shoulder Girdle to the Thorax as an Aid in Diagnosing Neurogenic Thoracic Outlet Syndrome. The Journal of Hand Surgery, 37, 1187-1193. https://doi.org/10.1016/j.jhsa.2012.02.022

[48] Rietveld, A.B. (2013) Dancers' and Musicians' Injuries. Clinical Rheumatology, 32, 425-344. https://doi.org/10.1007/s10067-013-2184-8

[49] Al-Shekhlee, A. and Katirji, B. (2003) Spinal Accessory Neuropathy, Droopy Shoulder, and Thoracic Outlet Syndrome. Muscle Nerve, 28, 383-385.

https://doi.org/10.1002/mus.10437

[50] Lawrence, R.L., Braman, J.P., Laprade, R.F. and Ludewig, P.M. (2014) Comparison of 3-Dimensional Shoulder Complex Kinematics in Individuals with and without Shoulder Pain, Part 1: Sternoclavicular, Acromioclavicular, and Scapulothoracic joints. Journal of Orthopaedic \& Sports Physical Therapy, 44, 636-645. https://doi.org/10.2519/jospt.2014.5339

[51] Lawrence, R.L., Braman, J.P., Staker, J.L., Laprade, R.F. and Ludewig, P.M. (2014) Comparison of 3-Dimensional Shoulder Complex Kinematics in Individuals with and without Shoulder Pain, Part 2: Glenohumeral Joint. Journal of Orthopaedic \& Sports Physical Therapy, 44, 646-655. https://doi.org/10.2519/jospt.2014.5556

[52] Buchberger, D.J. (1999) Introduction of a New Physical Examination Procedure for the Differentiation of Acromioclavicular Joint Lesions and Subacromial Impingement. Journal of Manipulative and Physiological Therapeutics, 22, 316-321. https://doi.org/10.1016/S0161-4754(99)70064-3

[53] Nakazawa, M., Nimura, A., Mochizuki, T., Koizumi, M., Sato, T. and Akita, K. (2016) The Orientation and Variation of the Acromioclavicular Ligament: An Anatomic Study. The American Journal of Sports Medicine, 44, 2690-2695. https://doi.org/10.1177/0363546516651440

[54] Ebraheim, N.A., Whitehead, J.L., Alla, S.R., Moral, M.Z., Castillo, S., McCollough, A.L., Yeasting, R.A. and Liu, J. (2011) The Suprascapular Nerve and Its Articular Branch to the Acromioclavicular Joint: An Anatomic Study. Journal of Shoulder and Elbow Surgery, 20, e13-e17. https://doi.org/10.1016/j.jse.2010.09.004

[55] Zanca, G.G., Oliveira, A.B., Ansanello, W., Barros, F.C. and Mattiello, S.M. (2014) EMG of Upper Trapezius-Electrode Sites and Association with Clavicular Kinematics. Journal of Electromyography and Kinesiology, 24, 868-874. https://doi.org/10.1016/j.jelekin.2014.06.012

[56] Korbon, G.A., Carron, H. and Lander, C.J. (1989) First Rib Palpation: A Safer, Easier Technique for Supraclavicular Brachial Plexus Block. Anesthesia \& Analgesia, 68, 682-685. https://doi.org/10.1213/00000539-198905000-00023

[57] Royse, C.E., Sha, S., Soeding, P.F. and Royse, A.G. (2006) Anatomical Study of the Brachial Plexus Using Surface Ultrasound. Anaesthesia and Intensive Care, 34, 203-210.

[58] Bordoni, B. and Bordoni, G. (2015) Reflections on Osteopathic Fascia Treatment in the Peripheral Nervous System. Journal of Pain Research, 8, 735-740. 
https://doi.org/10.2147/JPR.S89393

[59] Sucher, B.M. (2011) Ultrasonography-Guided Osteopathic Manipulative Treatment for a Patient with Thoracic Outlet Syndrome. The Journal of the American Osteopathic Association, 111, 543-547. https://doi.org/10.7556/jaoa.2011.111.9.543

[60] Demondion, X., Bacqueville, E., Paul, C., Duquesnoy, B., Hachulla, E. and Cotton, A. (2003) Thoracic Outlet: Assessment with MR Imaging in Asymptomatic and Symptomatic Populations. Radiology, 227, 461-468. https://doi.org/10.1148/radiol.2272012111

[61] Shah, V.M. and Routatal, R.V. (2015) Structure of Clavicle in Relation to Weight Transmission. Journal of Clinical and Diagnostic Research, 9, AC01-AC04. https://doi.org/10.7860/JCDR/2015/13901.6243

[62] Jurik, A.G., Møller, B.N., Jensen, M.K., Jensen, J.T. and Graudal, H. (1986) Sclerosis and Hyperostosis of the Manubrium Sterni. Rheumatology International, 6, 171-178. https://doi.org/10.1007/BF00541284

[63] Collins, J.D., Saxton, E.H., Miller, T.Q., Ahn, S.S., Gelabert, H. and Carnes, A. (2003) Scheuermann's Disease as a Model Displaying the Mechanism of Venous Obstruction in Thoracic Outlet Syndrome and Migraine Patients: MRI and MRA. Journal of the National Medical Association, 95, 298-306.

[64] Frosi, G., Sulli, A., Testa, M. and Cutolo, M. (2004) The Sterno-Clavicular Joint: Anatomy, Biomechanic, Clinical Features and Aspects of Manual Therapy. Reumatismo, 56, 82-88.

[65] Jurik, A.G., Zejden, A., Lambert, R.G., Rufibach, K., Hodler, J., Maksymowych, W.P., Duewell, S., Kissling, R.O. and Weber, U. (2013) Pitfalls in MR Morphology of the Sterno-Costo-Clavicular Region Using Whole-Body MRI. Clinical Radiology, 68, 785-791. https://doi.org/10.1016/j.crad.2013.02.007

[66] Olinger, A.B. and Homier, P. (2010) Functional Anatomy of Human Scalene Musculature: Rotation of the Cervical Spine. Journal of Manipulative and Physiological Therapeutics, 33, 594-602. https://doi.org/10.1016/j.jmpt.2010.08.015

[67] Ihnatsenka, B. and Boezaart, A.P. (2010) Applied Sonoanatomy of the Posterior Triangle of the Neck. International Journal of Shoulder Surgery, 4, 63-74. https://doi.org/10.4103/0973-6042.76963

[68] Segizbaeva, M.O., Donina, Z.A., Timofeev, N.N., Korolyov, Y.N., Golubev, V.N. and Aleksandrova, N.P. (2013) EMG Analysis of Human Inspiratory Muscle Resistance to Fatigue during Exercise. Advances in Experimental Medicine and Biology, 788, 197-205. https://doi.org/10.1007/978-94-007-6627-3_29

[69] Kang, J.I., Jeong, D.K. and Choi, H. (2016) The Effects of Breathing Exercise Types on Respiratory Muscle Activity and Body Function in Patients with Mild Chronic Obstructive Pulmonary Disease. Journal of Physical Therapy Science, 28, 500-505.

[70] Ferrante, M.A. and Ferrante, N.D. (2017) The Thoracic Outlet Syndromes: Part 1. Overview of the Thoracic Outlet Syndromes and Review of True Neurogenic Thoracic Outlet Syndrome. Muscle Nerve, 55, 782-793.

https://doi.org/10.1002/mus.25536

[71] Ferrante, M.A. and Ferrante, N.D. (2017) The Thoracic Outlet Syndromes: Part 2. The Arterial, Venous, Neurovascular, and Disputed Thoracic Outlet Syndromes. Muscle Nerve, 56, 663-673. https://doi.org/10.1002/mus.25535 